\title{
Erratum to: Microfacies and environmental study of the Mishrif Formation in Noor Field
}

\author{
Afrah Hasan Saleh Al-Ekabi
}

Published online: 12 February 2015

(C) Saudi Society for Geosciences 2015

\section{Erratum to: Arab J Geosci \\ DOI 10.1007/s12517-014-1589-2}

The original version of this article, regrettably, contained errors. Figure images and captions did match, except for Figs. 1, 2 and 3.

The correct images and captions are given in this article.

The online version of the original article can be found at http://dx.doi.org/ 10.1007/s12517-014-1589-2.

A. H. S. Al-Ekabi $(\bowtie)$

Department of Geology, College of Science, University of Baghdad,

Baghdad, Iraq

e-mail: d.afrah@yahoo.com 


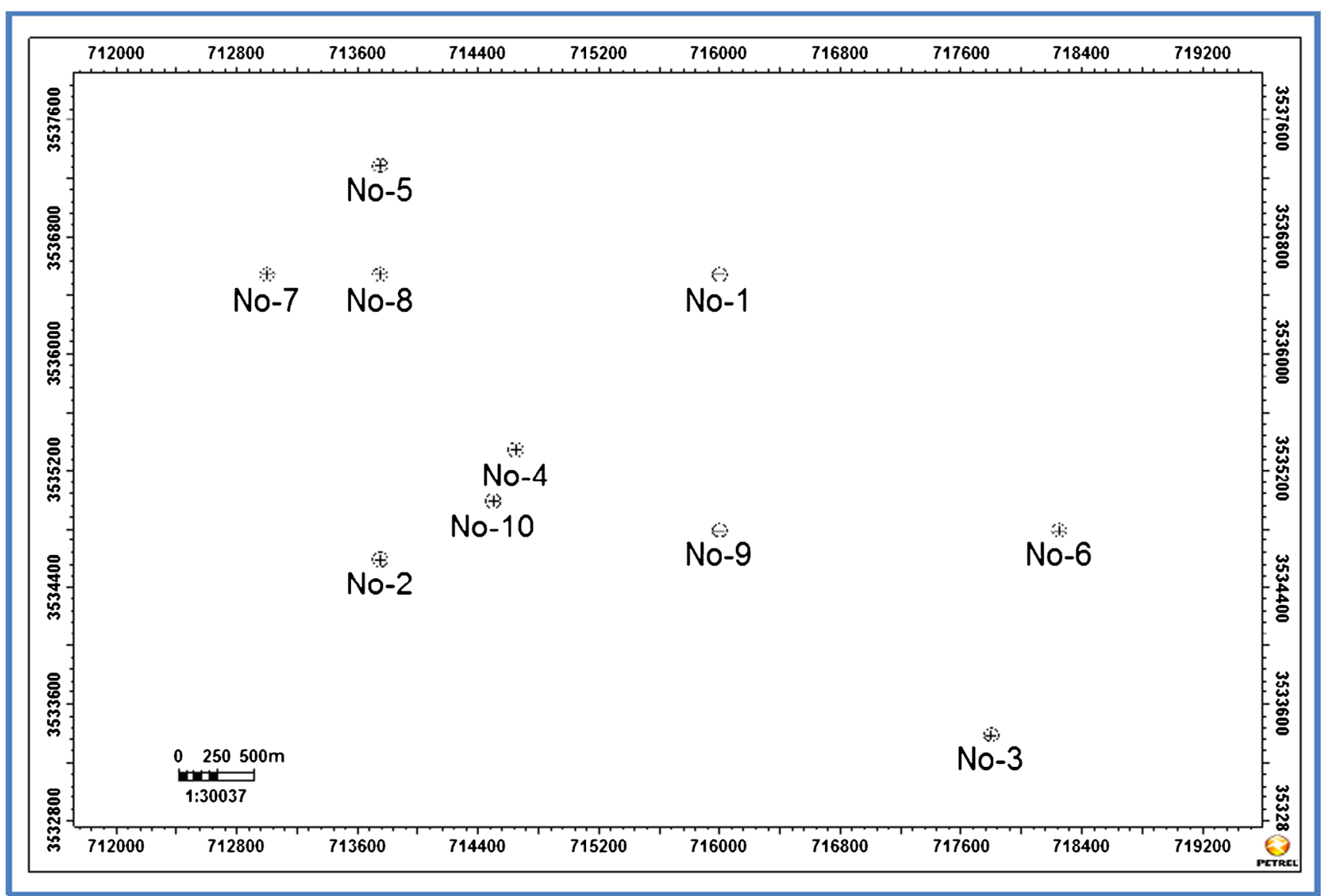

Fig. 1 Location map showing the distribution of the studied wells 


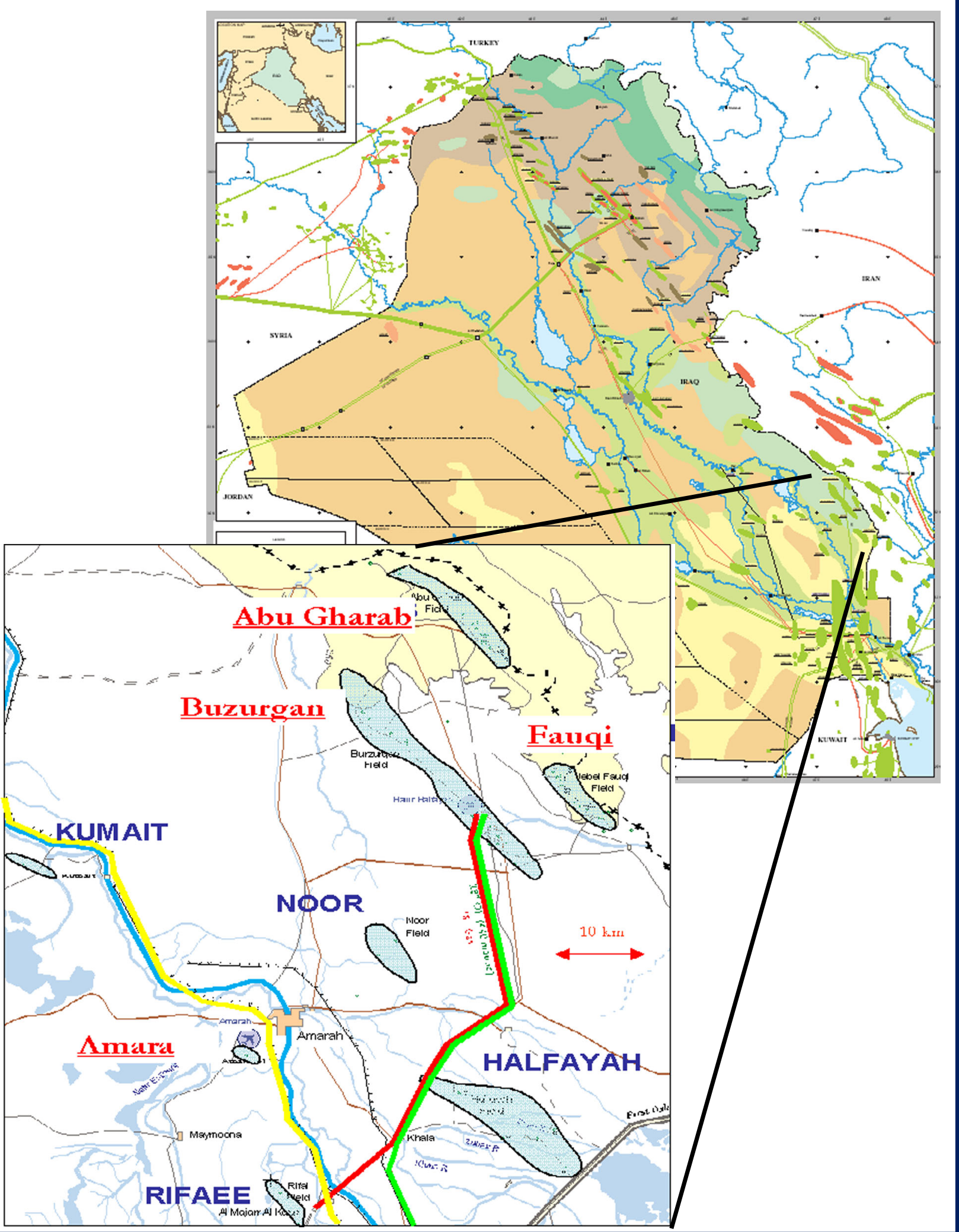

Fig. 2 Map of Iraq and the Noor oil field location 


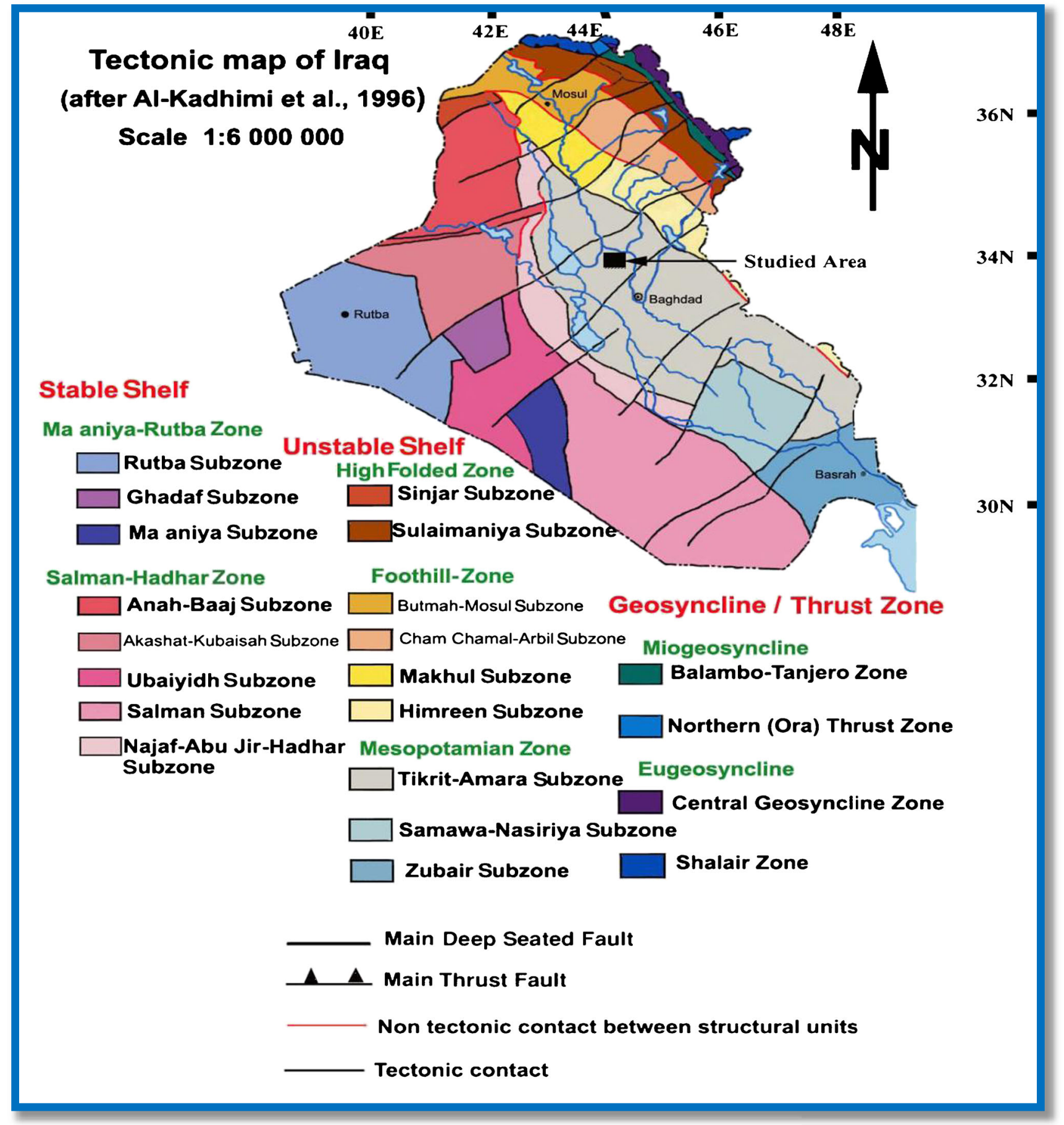

Fig. 3 Tectonic map of Iraq (Al-Khadhimi et al. 1996) 


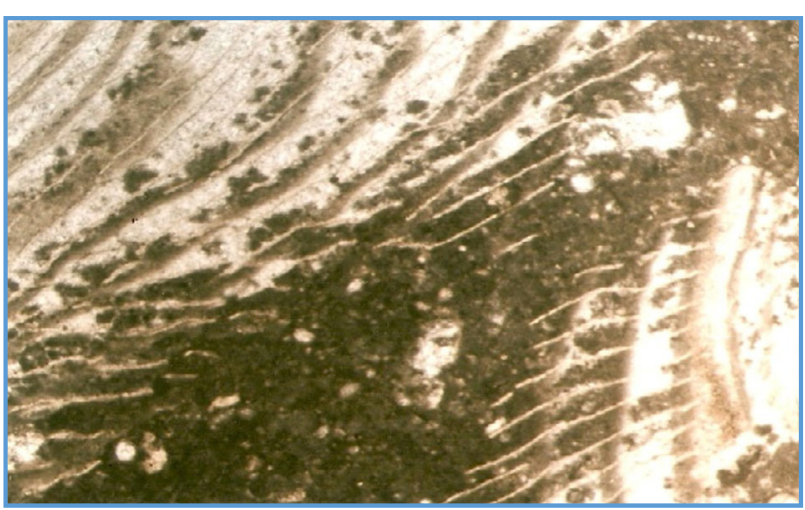

$1-1$

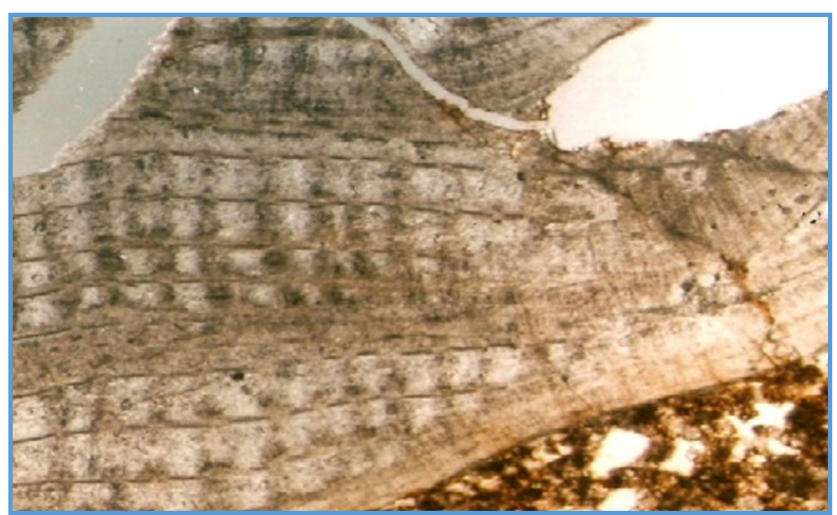

$1-2$

Plate 1 1-1 Rudist in grainstone (no. 1,3,342.64 m, $\times 35$ ). 1-2 Rudist and coral in grainstone (no. $1,3,338 \mathrm{~m}, \times 10$ )

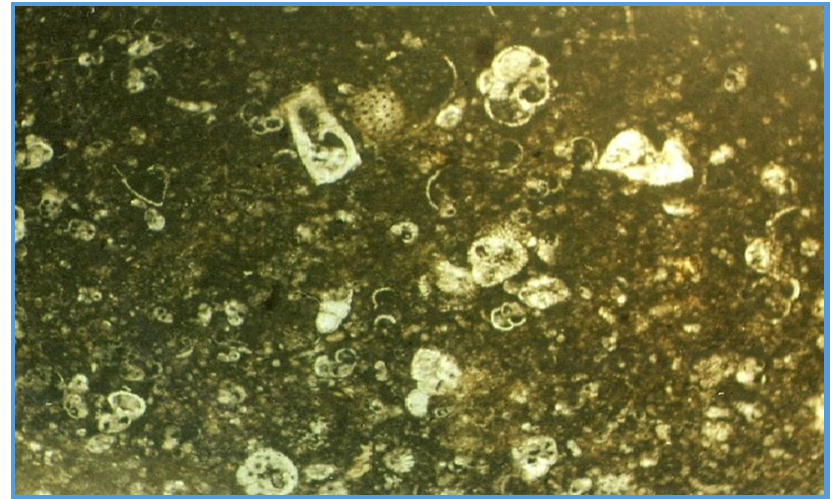

2-1

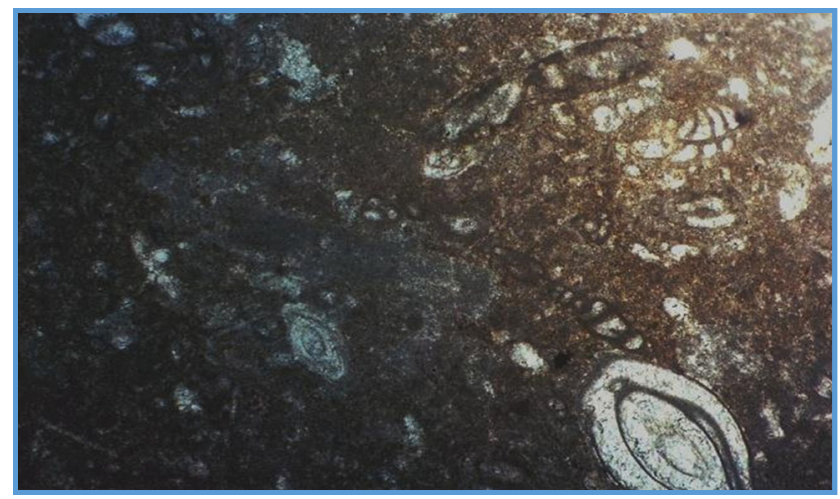

2-2

Plate 2 2-1 Planktonic Foraminifera (no. 1, 3,351.75 m, ×40). 2-2 Benthonic Foraminifera (no. 1, 3,353.75 m, $\times 40$ 


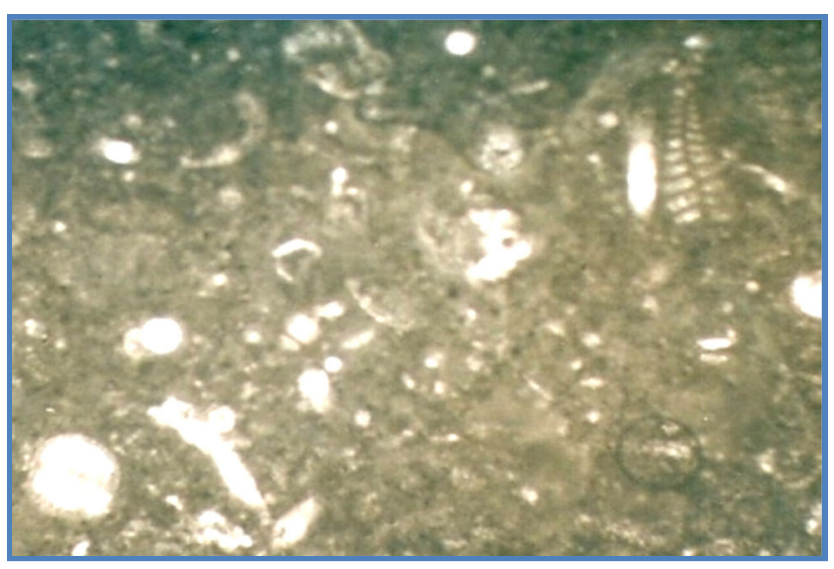

3-1



3-2

Plate 3 3-1 Calcareous algae and pelloids (no. 1, 3,372.5 m, $\times 35$ ). 3-2 Ooids (no. 2, 3,415.1 m, ×35)

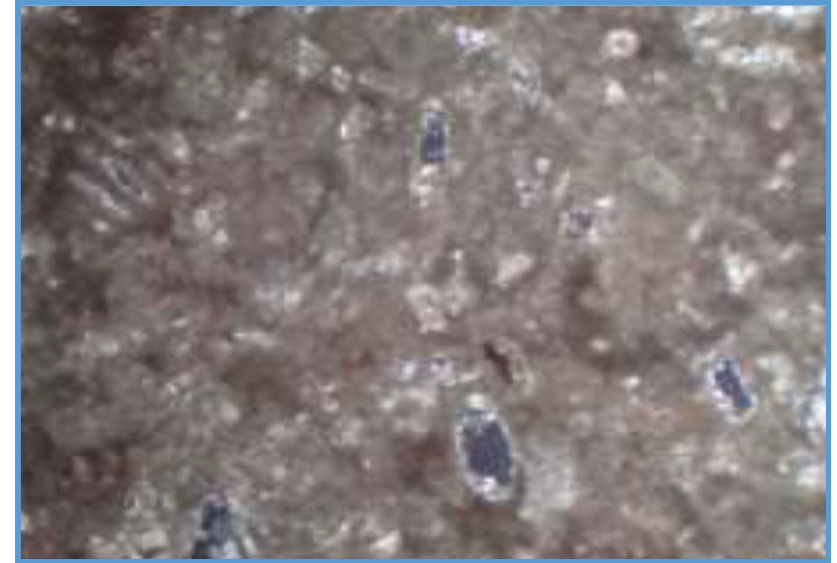

4-1

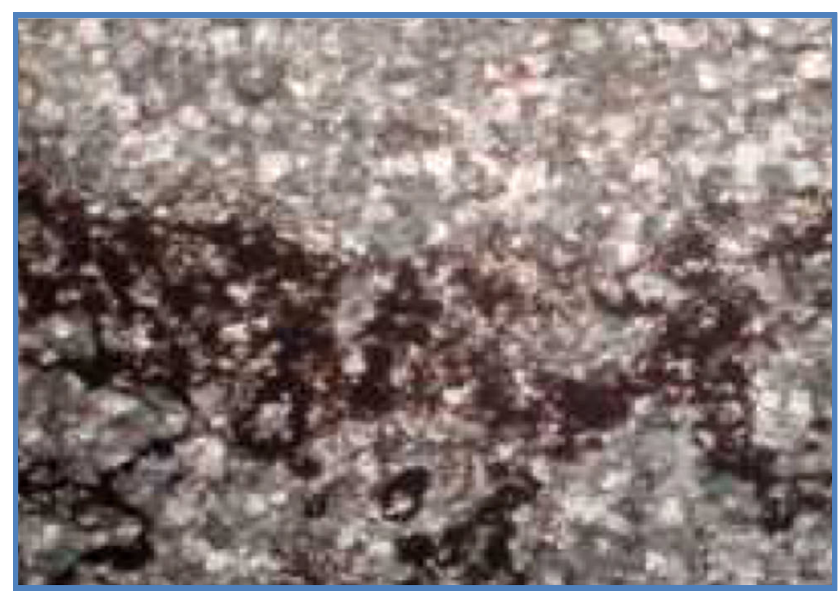

4-2

Plate 4 4-1 Micrite and sparite (no. 2, 3,414.2 m, ×35). 4-2 Dolomitization process $(3,417.2 \mathrm{~m}$, no. 2 


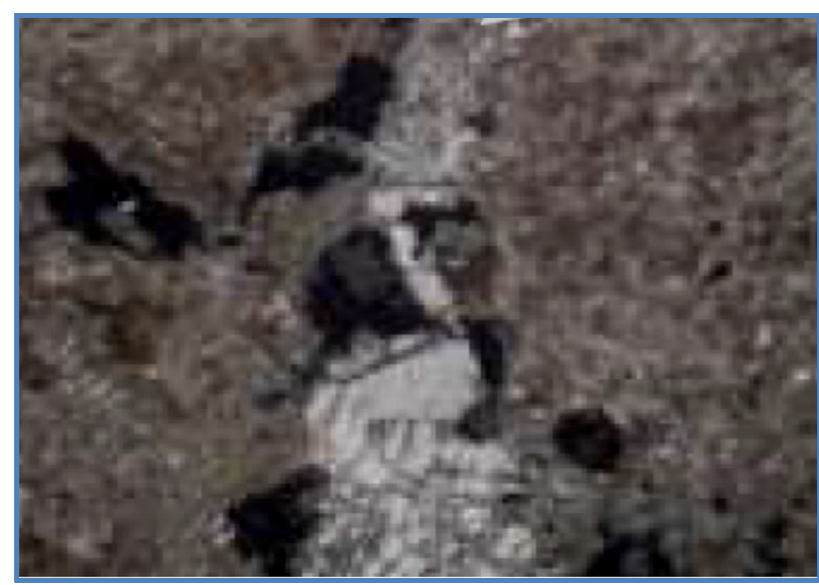

$5-1$

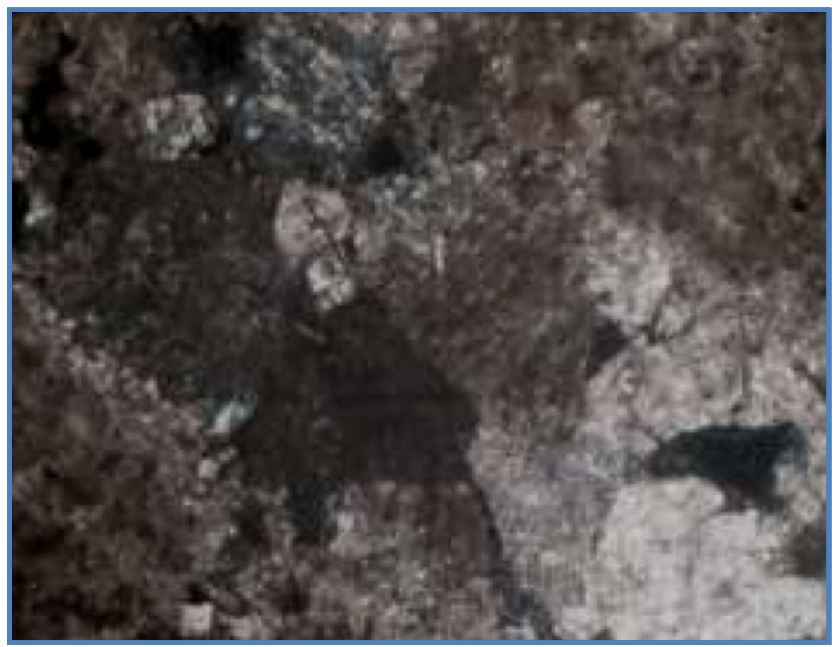

$5-2$

Plate 5 5-1 Dissolution process (no. 2, 3,418.2 m). 5-2 Cementation process (no. 2, 3,417.5 m)

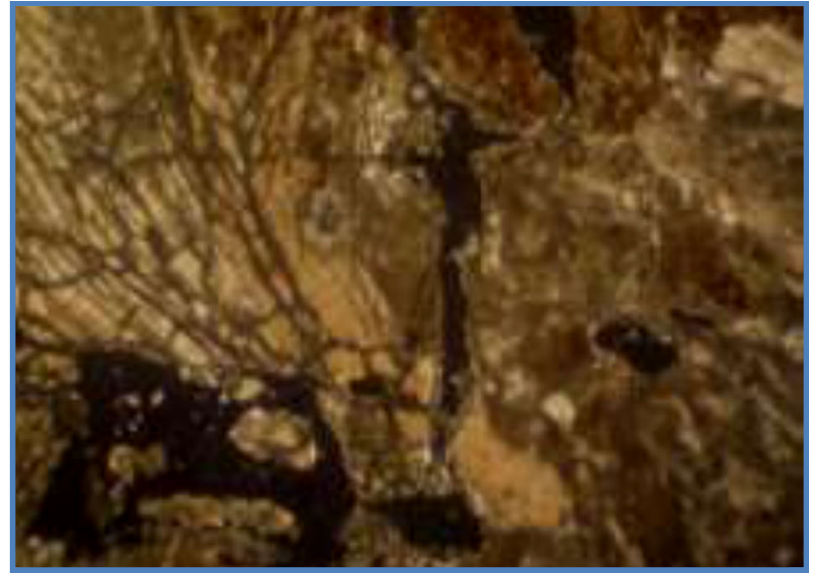

$6-1$

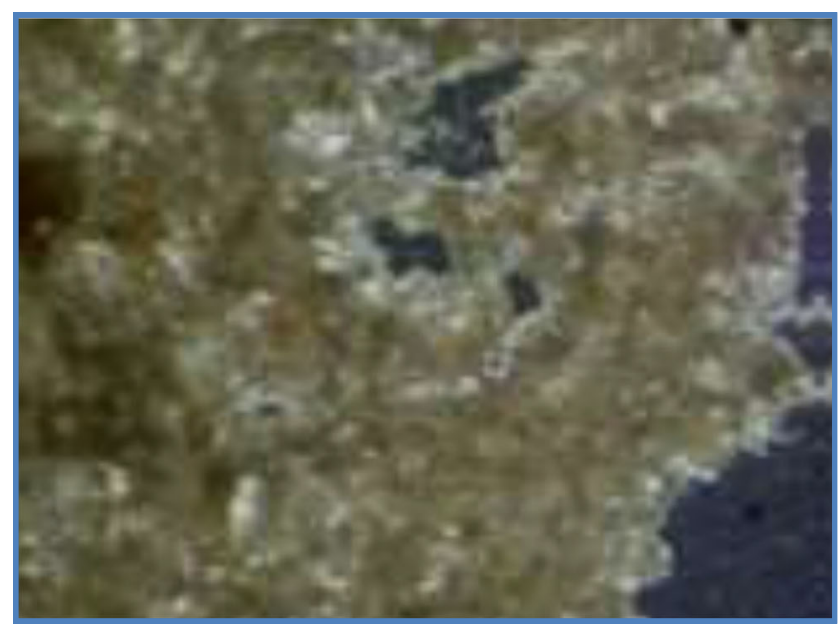

6-2

Plate 6 6-1 Micritization process (no. 2, 3,413.10 m, ×30). 6-2 Recrystallization process $(3,413.41 \mathrm{~m}, \times 10)$ 


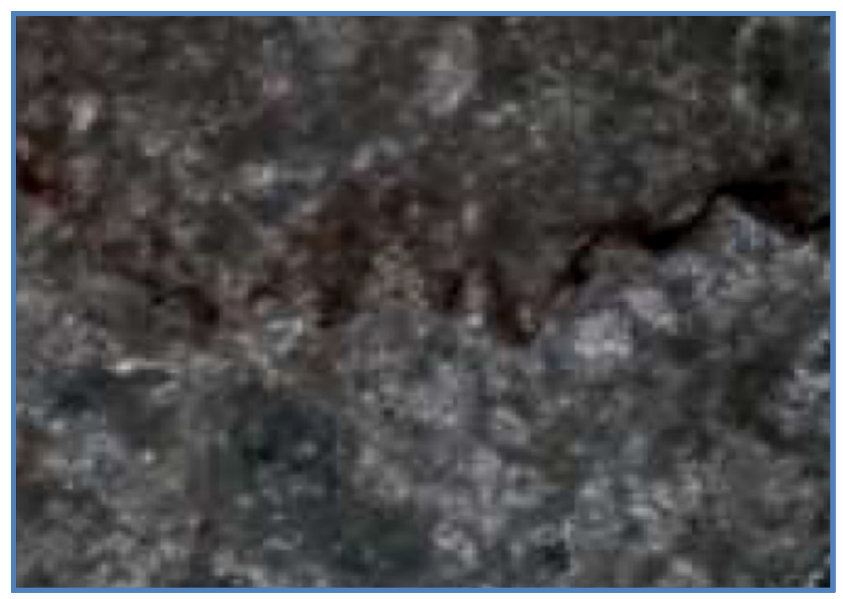

$7-1$

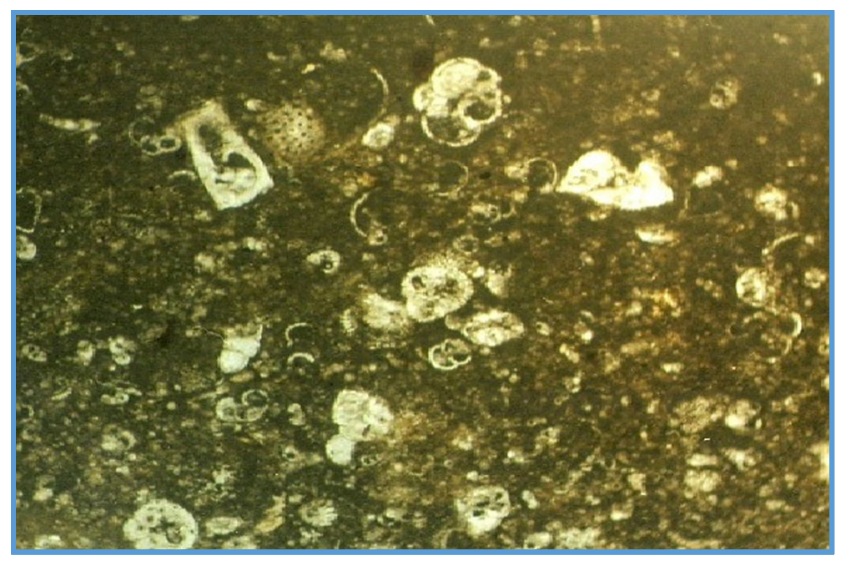

$7-2$

Plate 7 7-1 Stylolite process (pressure solution; no. 2, 3,416.3 m). 7-2

Deep marine environment (no. 1, 3,351.75 m, ×40) 


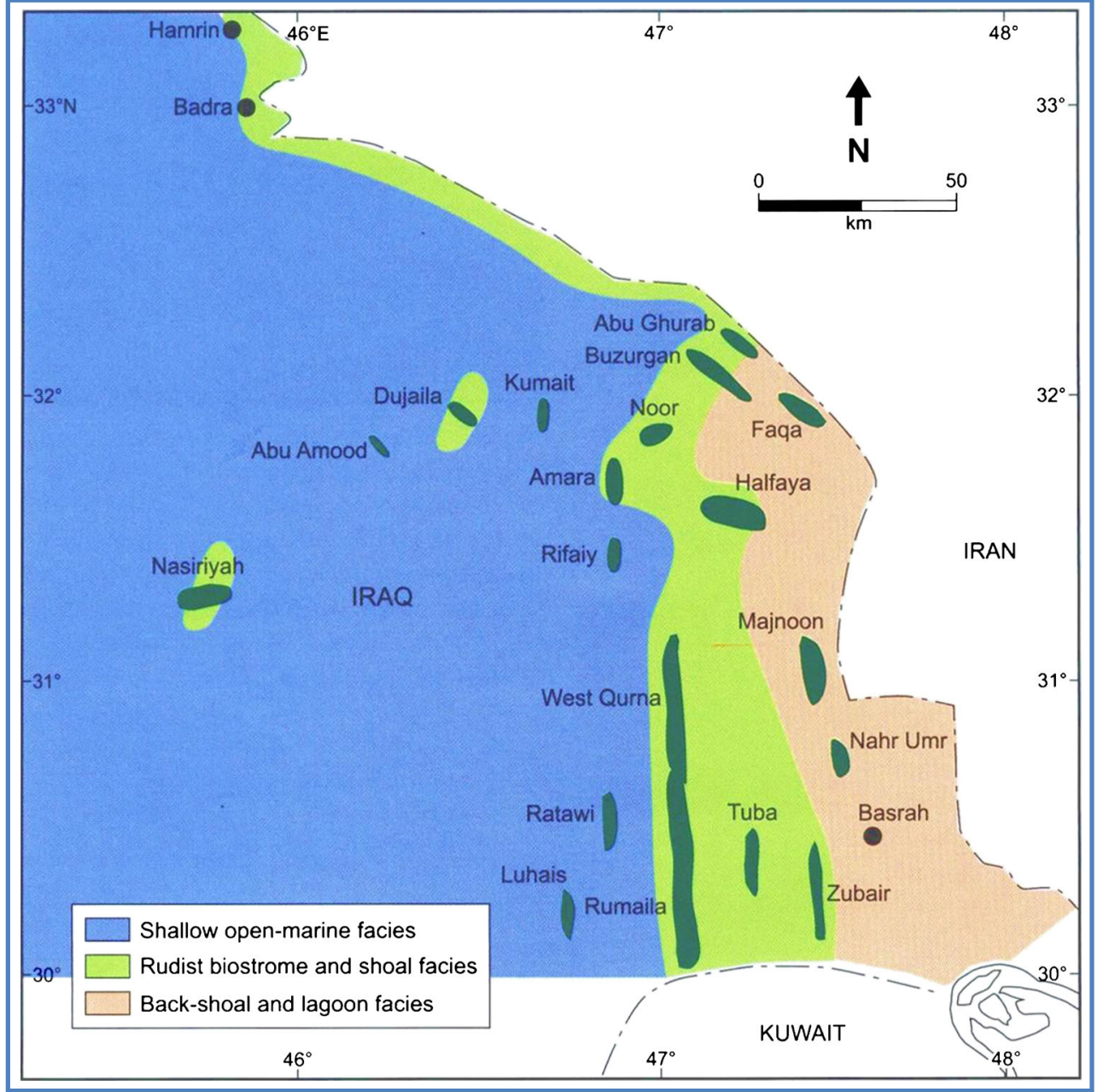

Fig. 4 Regional paleogeographic map showing facies distribution of the Mishrif Formation, southern Mesopotamian Basin (compiled from Buday 1980; Al-Mashhadani 1986; Aqrawi et al. 1998; Sadooni 2005; Jassim and Goff 2006; Aqrawi et al. 2010)

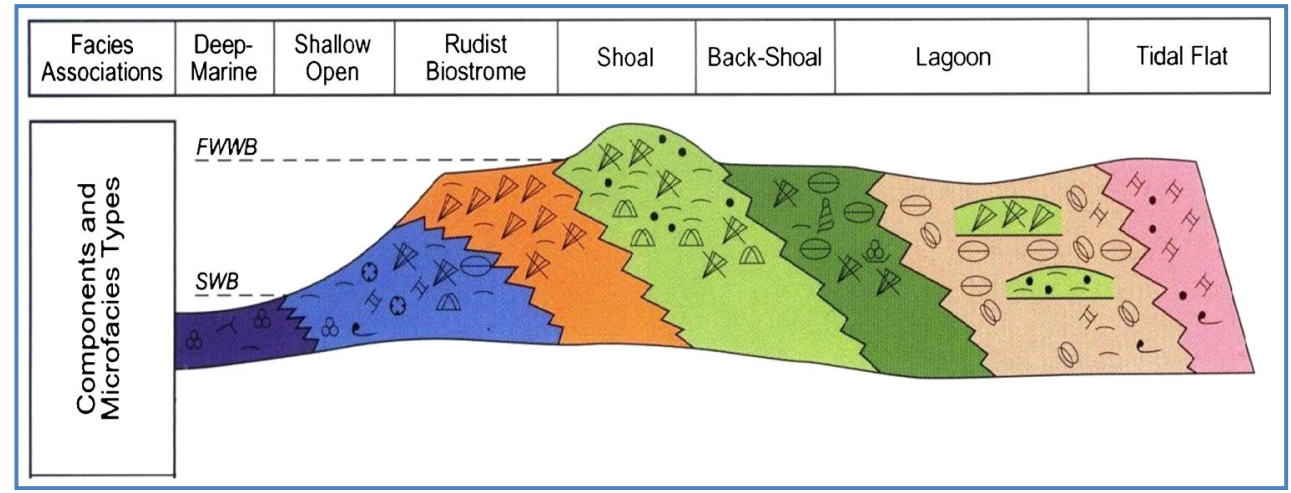

Fig. 5 Conceptual deposition environmental model for Mishrif carbonate platform 


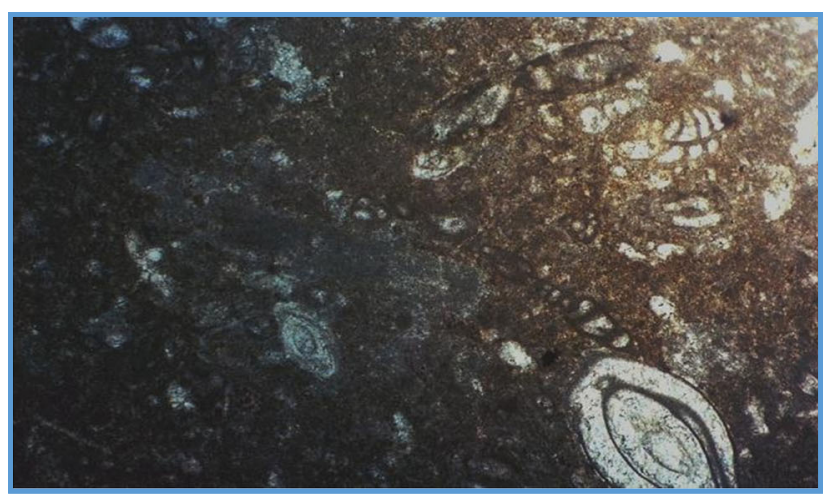

8-1

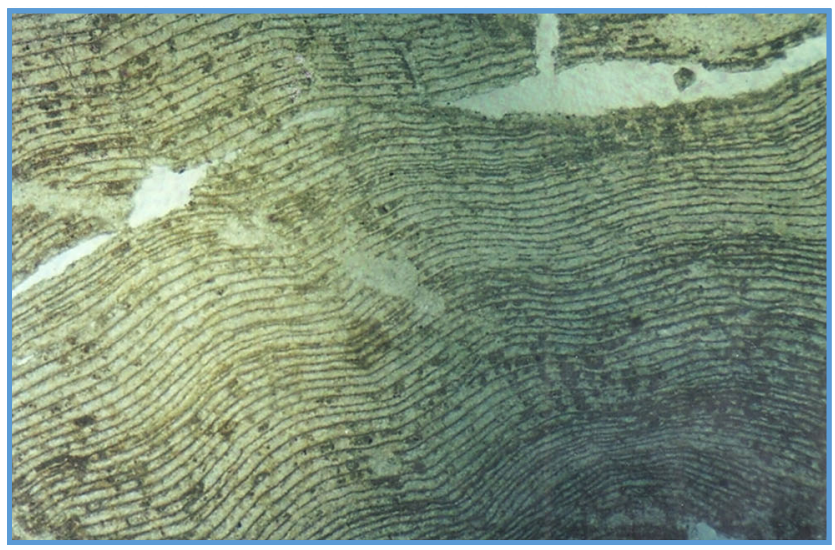

8-2

Plate 8 8-1 Shallow open marine environment (no. 1, 3,353.75 m, $\times 40$ ). 8-2 Rudist biostrome environment (no. 1, 3,341.64 m, ×35)

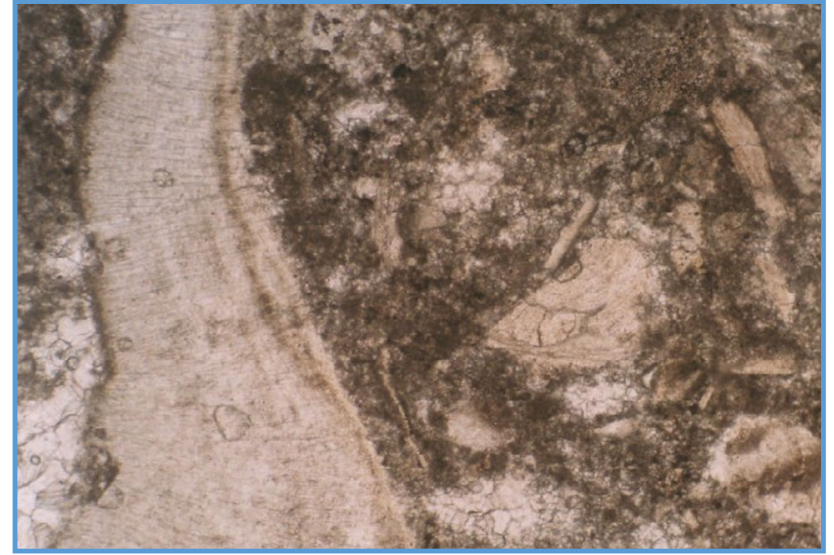

9-1

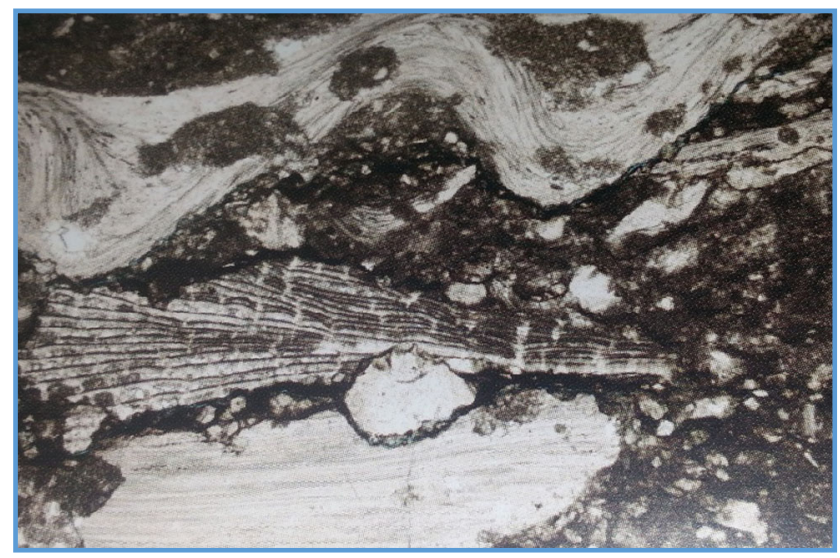

9-2

Plate 9 9-1 Rudist shell fragments (shoal environment; no. 1, 3,374 m, $\times 35$ ). 9-2 Chondrodonta shells and rudist fragment (back shoal environment; no. 1, C-7, 3,424.5 m) 


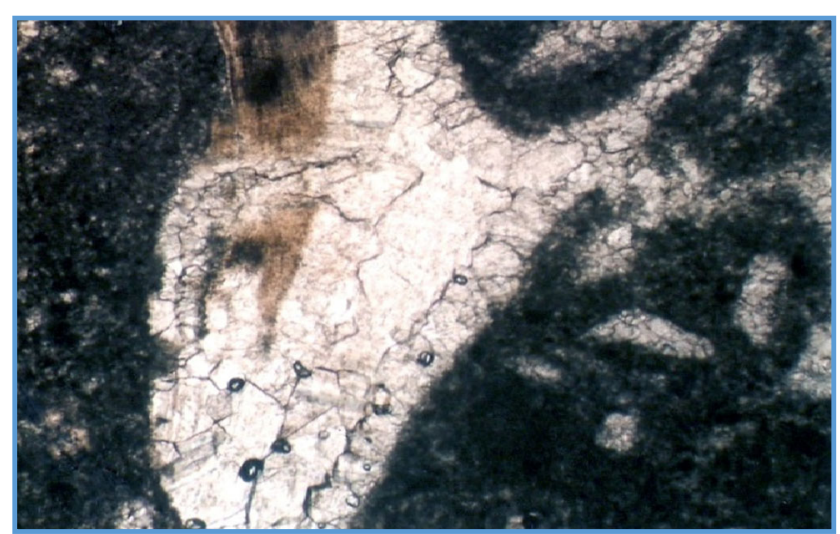

$10-1$

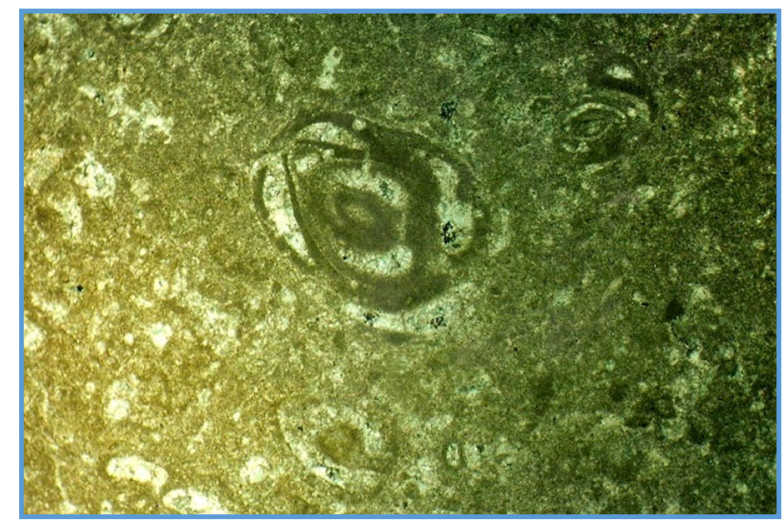

$10-1$

Plate 10 10-1 Rudist shell fragment (back shoal environment, no. 1, 3,407.3 m, ×30). 10-1 Miliolid Foraminifera (lagoon environment; no. $1,3,356.70 \mathrm{~m}$

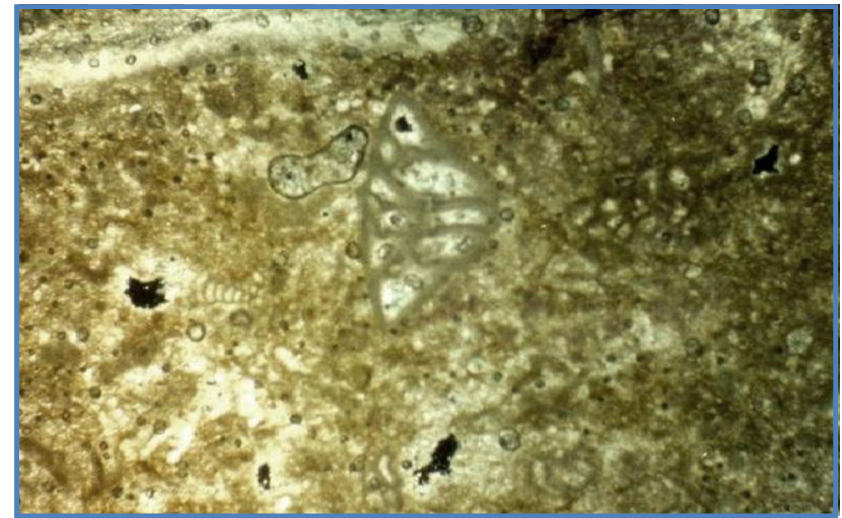

$11-1$

Plate 11 11-1 Nezzazata Foraminifera (lagoon environment, no. 1, $3,355.2 \mathrm{~m})$ 




Fig. 6 Cross sections in Mishrif Formation in well nos. 8, 4, and 3 


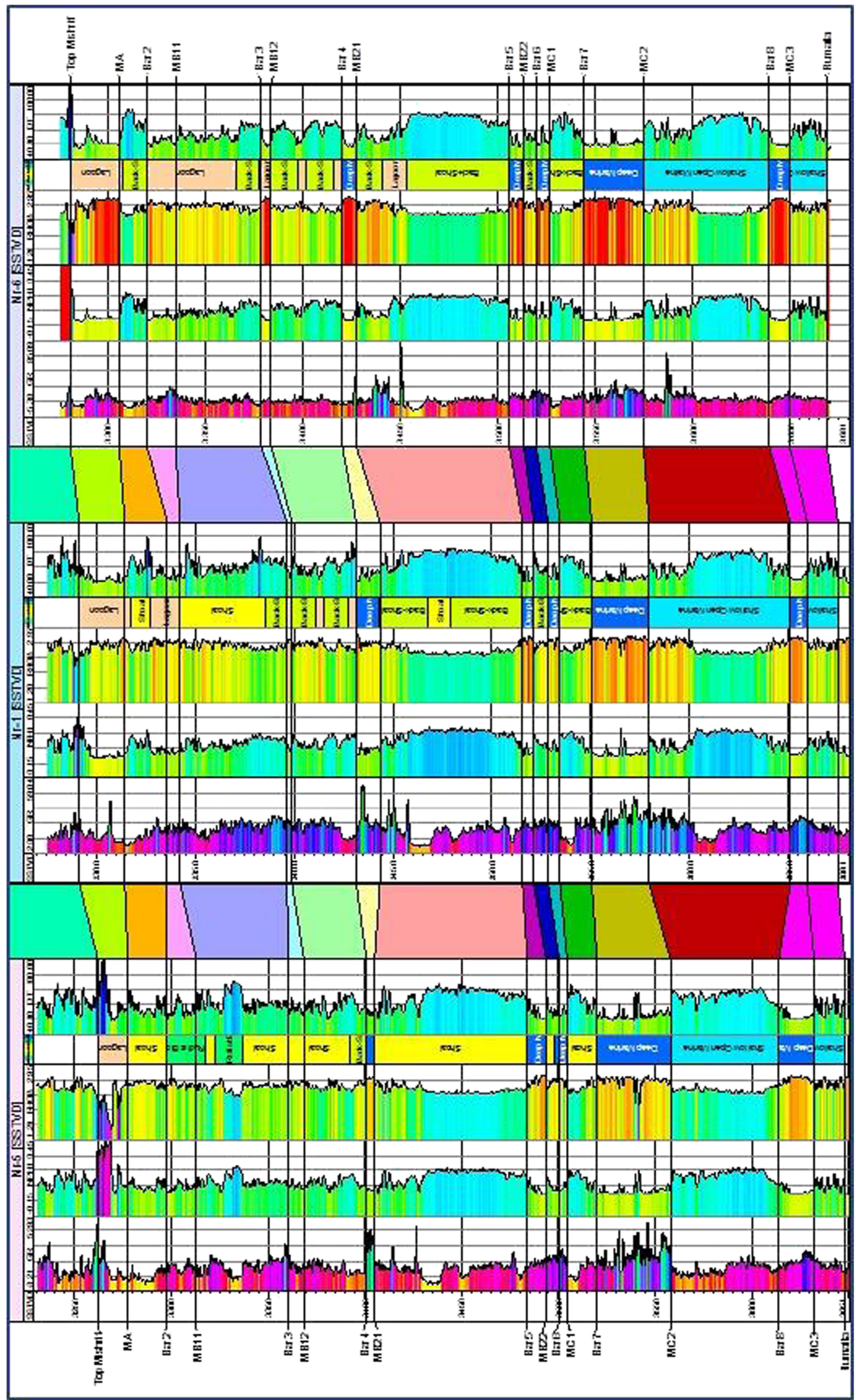

Fig. 7 Cross sections in Mishrif Formation in well nos. 5, 1, and 6 


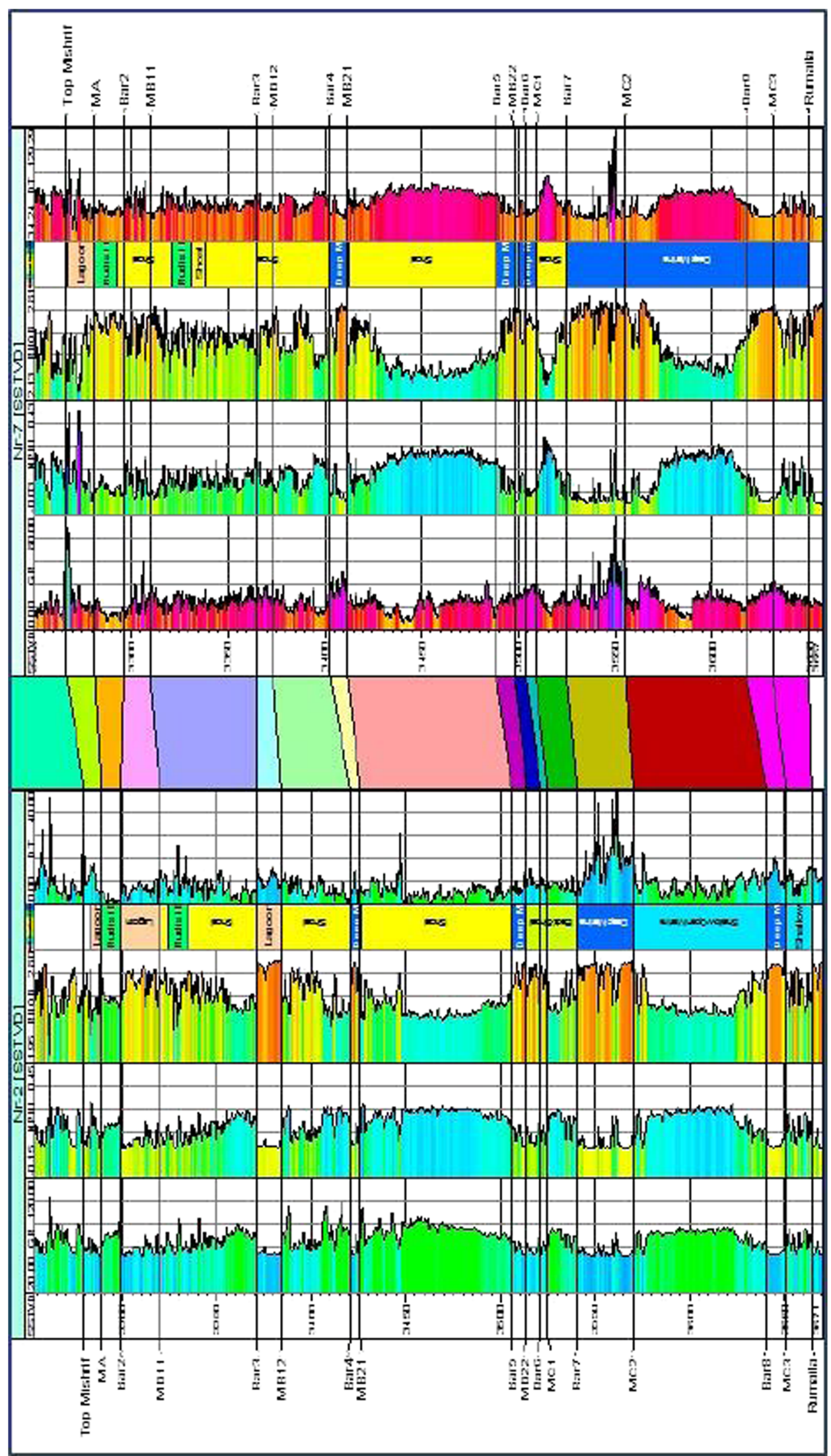

Fig. 8 Cross sections in Mishrif Formation in well nos. 2 and 7 